\title{
Normative Minor Childhood Stress and Risk of Later Adult Psychopathology in Saudi Arabia
}

\author{
Michael E. Hyland $^{1 *}$, Ahmed M. Alkhalaf ${ }^{2}$ and Ben Whalley ${ }^{1}$ \\ ${ }^{1}$ School of Psychology, Plymouth University, UK. \\ ${ }^{2}$ Faculty of Medicine, Albaha University, Saudi Arabia.
}

\begin{abstract}
Authors' contributions
This work was carried out in collaboration between all authors. Authors MEH, AMA and BW designed the study and wrote the protocol. Authors MEH and AMA managed the literature search. Author AMA collected the data. Author BW preformed the statistical analysis. Author

MEH wrote the first draft of the manuscript. All authors contributed to, read and approved the final manuscript.

Original Research Article

Received 21st November 2013

Accepted $26^{\text {th }}$ December 2013

Published $13^{\text {th }}$ January 2014
\end{abstract}

\section{ABSTRACT}

Chronic minor childhood stress in the form of corporal punishment predicts adult psychopathology in the United States but has not been demonstrated in a country where corporal punishment is normative. We tested whether adult psychopathology was predicted by recalled frequency of childhood corporal punishment and recalled controllability of punishment in Saudi Arabia. Two hundred and fifty nine Saudi men with substance addictions (who for cultural reasons were at risk for depression) completed a survey measuring: demographic variables, frequency of beating and controllability of punishment as a child, depression and borderline personality disorder symptoms (BPD). Beating frequency and punishment control were uncorrelated and unrelated to patients' or parents' education. 92 men $(36 \%)$ had major depression (PHQ-9 $\geq 15)$. Compared to those never beaten, those experiencing infrequent beating (once or twice a year) were significantly more likely to have major depression and higher BPD symptoms, after controlling for demographic variables. Those experiencing frequent beating (monthly or more frequent) were more likely to have major depression and higher BDP symptoms compared to those never beaten, but only when perceived control was low. Perceived punishment control was not significantly related to outcome for those who never had or had infrequent corporal punishment. These results provide evidence in a culture where corporal punishment is normative that corporal punishment, even when infrequent, 
predisposes to adult psychopathology and that uncontrollability increases the pathogenic effect of frequent corporal punishment. These results support the hypothesis that frequent minor stressors in childhood act as kindling factor for later depression.

Keywords: Physical punishment; controllability; depression; borderline personality disorder.

\section{NORMATIVE MINOR CHILDHOOD STRESS AND RISK OF LATER ADULT PSYCHOPATHOLOGY IN SAUDI ARABIA}

The United Nations recommends a ban on all forms of corporal punishment [1] but fewer than 30 countries have legislated to make it illegal in the school and home [2,3]. The recommendation for a ban is based on a substantial body of literature showing a statistical association between corporal punishment and childhood behavioral problems [4,5]. Although there is a large body of data showing that child abuse and major life stressors are associated with psychiatric disease [6], to date only one study shows a statistical association between corporal punishment in childhood and adult psychopathology, and which included major depression [6]. This last study was carried out using general population data in the United States, a country where federal law permits corporal punishment in the home and in school, but where there is a significant opposition to corporal punishment, including opposition from the American Academy of Pediatrics [2].

The possibility that corporal punishment plays a predisposing or causal role in psychopathology has implications for underlying processes. The statistical association between major stress and depression in adulthood is well established. Evidence supports the 'kindling' model-that a major stressor can sensitize for the development of later depression such that after the initial event, either minor stressors can precipitate depression (stress sensitization model) or because after the initial event, depression can develop even in the absence of later stressor (stress autonomy model) $[7,8]$. Although several theories predict that both major and chronic minor stress can act to kindle depression, empirical research has focused on major stressors because minor stressors pose measurement problems [7]. If repetitive minor stress, within the normal range of parenting style, predisposes to depression then "less noxious but still troublesome life events may possess important psychological consequences" [7]. By contrast, if corporal punishment does not predispose to later depression then this suggests that only major stressors are involved in kindling.

\subsection{Associations between Corporal Punishment and Adult Psychopathology}

Some authors suggest that there is no causal relationship between corporal punishment and childhood behavioral problems, despite the statistical relationship. There are two reasons for questioning a causal link, both of which apply to the statistical relationship between corporal punishment and psychopathology observed in the United States [6].

First, the causal direction between corporal punishment and behavioral problems may be reversed: naughty children might elicit more beating. Both corporal punishment and verbal punishment are associated with worse behavior [9], leading to the conclusion that children who are naturally badly behaved elicit more punishment, irrespective of the type of punishment. However, other studies lead to the opposite conclusion: The child's aggression 
at an early age predicted neither later physical nor verbal punishment [10], suggesting that naturally aggressive children do not elicit more corporal punishment.

Second, the correlation between corporal punishment and poor behavior is found in European or European-American samples but is often not found in Latin-American or African-American communities, where spanking is considered normal [11-13]. If spanking leads to behavioral problems only where it is non-normative then other, unobserved correlates of spanking, such as inconsistency of punishment or lack of parental warmth may be the true cause of poor behavior [14]. Although the correlation between corporal punishment and bad behavior is reported in some studies even when beating is normativebut normativeness moderates this relationship [15,16]— some conclude that there is insufficient evidence to ban corporal punishment [14,9].

Because of these criticisms, it is possible that the statistical association between corporal punishment and adult depression is not because minor stress (in the form of corporal punishment) predisposes to depression, as suggested by Afifi and colleagues [6] but due to a confound with other aspects of parenting or via an extension of the reversed causality argument, that naughty children are more likely to become depressed when adult. The study by Afifi and colleagues controlled for socio-economic status but such statistical control can be criticized as being incomplete. A study conducted in a country where corporal punishment was unrelated to socio-economic status would therefore provide another type of evidence of a causal link between corporal punishment and psychopathology, if that causal link exists.

Inconsistent punishment, either corporal or verbal, leads to perceived lack of control by the child. There is a well-established relationship between perceived uncontrollability and depression $[17,18]$ and underlying biological mechanisms have been identified $[19,20]$ as well as a relationship between uncontrollability and borderline personality disorder. Perceived lack of control increases the stress caused by an aversive stimulus and so corporal punishment should interact with the controllability of punishment, with frequent uncontrollable corporal punishments generating the worst outcomes.

This paper tests whether the frequency and controllability of corporal punishment in childhood predicts adult depression, and whether there is a statistical interaction between these two variables.

In Western countries the frequency of corporal punishment is inversely related to wealth. This inverse relationship between wealth and corporal punishment is not found in Arab countries [21], where beating with the hand or a stick is considered normal or even desirable [22] - a Western expression describes this attitude: 'spare the rod and spoil the child'. We carried out our study in Saudi Arabia and measured perceived frequency of corporal punishment in childhood and the controllability of punishment. Because the United States population data used by Afifi and colleagues [6] is unavailable in Saudi Arabia, our sample was taken from adults undergoing treatment for addictions. People with addictions are at greater risk of psychopathology in Western countries [23-25] but there is a reason why these individuals are of particular interest in Saudi Arabia. Saudi Arabia is an Islamic country where alcohol, recreational drugs, and gambling are all banned by the state. There are three references to alcohol in the Q'uran, in each case providing unambiguous prohibition. For example, the third reference (5:91, Al-Ma'idah) translates as: "Satan only wants to cause animosity and hatred between you through intoxicants and gambling and to avert you from the remembrance of Allah and from prayer. So will you not desist?" Children learn and 
memorize the Q'uran starting at home and preschool and continuing through classes on the Q'uran in each year of primary, intermediate and secondary school. The Q'uran therefore becomes internalized by Saudi citizens as a guide to living a good life. Some Saudis memorize the whole of the Q'uran by heart. Thus, if a person is an addict, it is not just a matter of shame but also of deep guilt because Saudi addicts may believe that what they are doing is fundamentally bad. Due to heightened guilt, Saudi addicts should be highly at risk of developing depression [26].

We measured two adult outcomes that are known to be associated with childhood abuse: depression and borderline personality disorder in order to determine whether they are also associated with corporal punishment and lack of punishment control.

\section{METHODS}

\subsection{Participants}

Men with substance addictions are referred by relatives (or self-refer) to the Al Amal Complex for Mental Health in Dammam, Saudi Arabia, which has a 150-bed ward for patients with substance addictions. Men are admitted only after psychiatric assessment indicating an urgent need for treatment. The length of stay varies but is usually in excess of 30 days. Inpatients at the addiction facility were invited to take part. There were no exclusion criteria.

\subsection{Assessments}

\subsubsection{Depression}

The Patient Health Questionnaire (PHQ-9) is a 9-item self-report measure of the severity of depression, with reliability of $\alpha=0.89$. Applying a threshold of $\geq 15$, the authors of the scale report sensitivity for a clinical diagnosis of Major Depressive Disorder (MDD) at $68 \%$, with specificity of $95 \%$ (Kroenke et al., 2010).

\subsubsection{Borderline personality disorder (BDP)}

Fifteen items from the semi-structured clinical interview for diagnosing DSM-IV Axis II Personality Disorders (SCID-II) [27] were used to screen patients for possible borderline personality disorder. When used to screen patients, items from the SCID-II are presented in a binary (yes/no) format and followed up in a semi-structured clinical interview for definitive diagnosis; our dataset includes the total number of item endorsements - a proxy for borderline symptomatology.

Beating frequency was assessed with a single question "Between the age of 6 and 18, were you beaten by your parents?" and with 8 response options varying between "Never" and "At least once every day" (see Table 1). The Arabic word for beating implies the use of either stick or hand and that the punishment is not excessive. Beating is the common form of corporal punishment in Saudi Arabia. Punishment control was assessed with a single question: Patients were asked to reflect on their worst punishment between the ages 6 and 18 and asked: "Were there things you could do to control the severity of punishment?" with a 7 -point response scale where $1=$ "unable to control" and $7=$ "able to control". Note that 
punishment control question did not specify the type of punishment so could include both corporal and other forms of punishment.

The following demographic details were also assessed: age, smoking status, the patient's education, marital status, and the education of the mother and father. All questions were presented in Arabic (available on request); back-translation was used for both the PHQ-9 questions and the SCID-II screening items to ensure consistency.

Table 1. Bivariate correlations of key study variables $(\mathrm{N}=\mathbf{2 5 9})$

\begin{tabular}{lllll}
\hline & BDP Score & PHQ-9 & $\begin{array}{l}\text { Beating } \\
\text { frequency }\end{array}$ & $\begin{array}{l}\text { Punishment } \\
\text { control }\end{array}$ \\
\hline 1. BPD score & & & \\
2. Depression (PHQ-9) & $.56^{* * *}$ & & & \\
3. Beating frequency & $.22^{* * *}$ & $.15^{* *}$ & & \\
4. Punishment control & -.06 & .05 & -.05 & .06 \\
5. Age & $-.15^{* *}$ & $-.14^{*}$ & .01 & .07 \\
6. Smoker & -.07 & -.09 & -.11 & -.02 \\
7. Patient's education & .08 & -.03 & -.01 & -.04 \\
8. Father's education & $.13^{*}$ & $.13^{*}$ & .05 & -.04 \\
9. Mother's education & $.13^{*}$ & .09 & .03 & \\
\hline
\end{tabular}

\section{PROCEDURE}

Patients were approached individually on the addiction ward by one of the authors (xxx) over a 3-month period, and invited to participate in an anonymous, confidential survey. Patients provided written informed consent. Ethical approval was obtained from the xxxx University Human ethics committee and the ethics committee of the Al Amal Complex for mental health.

\section{STATISTICAL ANALYSES}

Beating frequency was divided into three categories: no beating (never beaten, or beaten once only in life), infrequent beating (beaten once or twice per year) and frequent beating (beaten once per month or more frequently). Perceived control of punishment was divided into two categories: low (<4) and high $\geq 4)$. This division was post hoc based on the finding that the mean for all respondents was 3.9. Depression status (PHQ-9 $\geq 15)$ and BPD scores were regressed on the frequency of beating, reported controllability and the interaction of frequency and control, in two separate models (for depression status we used logistic regression). Demographic control variables (age, smoking status, education and the education of the patient's mother and father) were included in all models.

\section{RESULTS}

Two hundred and fifty nine men completed the assessments. Mean age was 32 years (SD = 8.2; range 19 to 58), $57 \%$ had received education to secondary school equivalent or greater, but $15 \%$ had received only elementary-level education or less. Educational status of parents was lower, with $30 \%$ of fathers and $42 \%$ of mothers receiving no education and only $22 \%$ of fathers and $16 \%$ of mother receiving education to secondary school level or greater. Fifty 
three $\%$ were single, $35 \%$ married and $10 \%$ divorced; one individual was widowed. Applying a PHQ-9 threshold of $\geq 15$ [28], 92 patients (36\%) met the criteria for major depressive disorder.

Table 1 displays bivariate correlations between the measures taken. Whereas some of the demographic variables predicted the two measures of psychopathology, no demographic variable was statistically associated with beating frequency or with the perceived control of punishment. Perceived control of punishment and beating frequency were uncorrelated. These results are consistent with the normality of beating in Saudi Arabia and its lack of relationship, as well as the relationship of punishment control, to socioeconomic status.

Table 2 shows the proportion of patients with major depression and mean BPD symptom scores, as a function of beating frequency and punishment control. Logistic regression and multiple regression revealed for depression significant main effects of beating frequency and punishment control as well as a significant interaction between these two variables, and for $B D P$ symptoms a significant main effect of beating frequency and an interaction between beating frequency and punishment control (see Table 3).

Table 2. Model estimated percentage of patients with major depression and mean borderline personality disorder (BPD) symptoms, by beating frequency and percieved control, controlling for demographic variables

\begin{tabular}{llllllll}
\hline Beatingfrequency & $\begin{array}{l}\text { Punishment } \\
\text { control }\end{array}$ & \multicolumn{4}{c}{ Major depression } & \multicolumn{2}{c}{ BPD symptoms } \\
\hline \multirow{3}{*}{ No beating } & & $\mathbf{N}^{1}$ & $\mathbf{N}^{2}$ & Proportion & SE & Mean & SE \\
\cline { 2 - 8 } Infrequent beating & Low & 62 & 14 & .23 & .05 & 7.16 & 0.48 \\
& High & 85 & 31 & .36 & .05 & 8.25 & 0.41 \\
Frequent beating & How & 19 & 11 & .58 & .11 & 10.16 & 0.87 \\
& How & 36 & 17 & .47 & .08 & 9.53 & 0.63 \\
& High & 30 & 15 & .50 & .09 & 11.10 & 0.69 \\
& High & 28 & 4 & .14 & .07 & 7.36 & 0.71 \\
\hline
\end{tabular}

${ }^{1}$ Number of people at this level of beating frequency and punishment control.

${ }^{2}$ Number of people at this level of beating frequency and punishment control who have major depression.

Table 3. Main effects of and interactions between beating frequency and punishment control, predicting borderline personality disorder (BPD) status and depression

\begin{tabular}{lllll}
\hline & BPD status & $\mathbf{( 0 / 1 )}$ & Depression & (PHQ-9) \\
\hline & $\mathbf{X}^{2}(\mathbf{d f})$ & $\mathbf{p}$ & $\mathbf{F}(\mathbf{d f})$ & $\mathbf{p}$ \\
\hline Beating Frequency & $9.02(2)$ & .011 & $7.35(2,253)$ & .001 \\
Punishment control & $2.74(1)$ & .098 & $4.26(1,253)$ & .040 \\
Interaction & $11.04(2)$ & .004 & $8.42(2,253)$ & .001 \\
\hline
\end{tabular}

We examined to what extent these significant effects were due to differences between no beating, infrequent beating or frequent beating. Irrespective of perceived control, infrequent beating $\left(x^{2}(1)=8.2, p<.01\right)$ was associated with more depression than no beating. However, there was no significant difference between frequent and no beating $\left(X^{2}(1)=0.00, p=.973\right)$. For BPD symptoms both infrequent $(F(1,253)=11.78, p<.001)$ and frequent beating $(F(1,253)=6.68, p=.010)$ produced worse outcomes than no beating. 
When there was no beating or infrequent beating, perceived punishment control had no significant effect on outcome (respectively, for depression, $\Delta=13 \%$ and $-11 \%, p=.07$ and .45 ; for BPD symptoms $\Delta=1.08$ and $-0.63, p=.07$ and .45 ). When beating was frequent, those perceiving that their punishment was controllable had significantly less depression than those perceiving their punishment as uncontrollable (respectively, for depression $\Delta=-36 \%$, $\mathrm{p}=.002$; for BPD symptoms $\Delta=-3.74, \mathrm{p}<.001$ ).

To further investigate the pattern of means in Table 2, we compared those people who reported frequent beating but experienced high levels of punishment control with those who experienced no beating (irrespective of level of control). There was no significant difference for depression $(F(1,172)=0.07, p=.79)$ or for BPD score $(F(1,172)=0.28, p=.59)$ showing that despite being beaten frequently, those perceiving high levels of control had no worse outcomes compared with those who were never beaten.

\section{DISCUSSION}

This study examined the risk of psychopathology in a group of people who, for cultural reasons, were prone to depression because of their addictions. The results of this study showed that there was a statistical relationship between beating and psychopathology but it depended on another aspect of parenting: the extent to which children perceive themselves to be in control of their punishment. Overall, the results confirm the hypothesis that minor stress is a predictor of major depression, even when the minor stress is normative. These findings are consistent with Afifi et al. [6] but contrast with the conclusion that authoritarian parenting when normative appears to have far less adverse effects then non-normative authoritarian parenting [29]. Thus, in contrast to some other aspects of parenting, corporal punishment and uncontrollability act as kindling for later depression, irrespective of cultural background.

The two measures of punishment style, namely, frequency of beating and controllability of punishment, were uncorrelated, showing these to be independent facets of parenting style in this population. Adults who reported never being beaten had less depression than those who reported they were beaten infrequently. For these two groups (no beating and infrequent beating) the perceived control of punishment did not affect frequency of depression. However, for those experiencing frequent beating, the perceived control of punishment had a highly significant effect on psychopathology: those with low punishment-control had more depression and BPD symptoms than those with high punishment-control. The protective effect of high punishment-control for those frequently beaten was clinically important. Those reporting frequent beating with high punishment-control had levels of psychopathology similar to those where were never beaten. By contrast, those who reported frequent beating with low punishment-control had levels of psychopathology similar to those who were infrequently beaten.

Our data show that even infrequent beating predisposes to psychopathology. There are several possible reasons for this finding, but it may be that infrequent beating in contrast to no beating is associated with other aspects of parenting that also have a bearing on outcome.

There are limitations to our study: We did not have objective measures of beating frequency or punishment controllability, and inaccuracies may arise from recall bias: in particular, it is a concern that current negative affect may increase recollections of aversive childhood experiences, either as part of a self-regulatory strategy to explain current affect, to elicit 
sympathy, or because negative events are more salient during periods of negative affect. In addition, it is possible that the perception of control is a dispositional feature of the participant rather than a behavior of the parent [30], in which case our observed interaction may be due to the way different types of people respond to beating. We used a clinical population in order to detect more frequent psychopathology, but we do not know whether our results generalize to other populations. We measured only major depression and BPD symptoms and the results may differ for less severe forms of psychopathology, for measures of wellbeing, or for other behavioral measures such as aggression. We assessed only males and there is some evidence that childhood experiences have a greater impact on depression for females rather than males [31]. Furthermore, research with a Chinese population demonstrates that corporal punishment predicts aggression in boys, whereas psychological coercion predicts aggression in girls [32]. Obviously, depression may have many causes other than corporal punishment.

Finally, this study provides a link between three strands of research. The first strand shows that early childhood trauma predisposes to adult somatic disease due to epigenetic changes that increase levels of inflammatory mediators and produce neurological changes [33], as well as predisposing to psychopathology [34]. The second strand shows that corporal punishment is associated with behavior problems in children $[4,5]$. The third strand shows that stress in adults produces long term changes that increase the risk of later depression $[35,7]$. Because depression is associated with increased levels of inflammatory mediators [36] as well as HPA-axis dysregulation [37], it is possible that all three phenomena (early and late life major stress and corporal punishment) involve a similar mechanism, where stress produce biological changes, including epigenetic changes, that then make the development of depression and as well as other psychiatric and somatic pathology more likely [38].

\section{COMPETING INTERESTS}

Authors have declared that no competing interests exist.

\section{REFERENCES}

1. UNICEF. Convention on the Rights of the Child; 2006.

Avalable: http://www.unicef.org/crc/index 30229.html.

2. Oates K. Physical punishment of children: can we continue to accept the status quo? J Paediatr Child Health. 2011;47:505-507.

3. Zolotor AJ, Puzia ME. Bans against corporal punishment: A systematic review of the laws, changes in attitudes and behaviours. Child Abuse Review. 2010;19:229-247.

4. Gershoff ET. Corporal punishment by parents and associated child behaviours and experiences: A meta-analytic and theoretical review. Psychol Bull. 2002;128:539-579.

5. Taylor CA, Manganello JA, Lee SL, Rice JC. Mothers' spanking of 3-year-old children and subsequent risk of children's aggressive behaviour. Pediatrics. 2010;125:e1057e1065.

6. Afifi TO, Brownridge DA, Cox BJ, Sareen J. Physical punishment, childhood abuse and psychiatric disorders. Child Abuse Negl. 2006;30:1093-1103.

7. Monroe SM, Harkness KL. Life stress, the "kindling" hypothesis and the recurrence of depression: Considerations from a life stress perspective. Psychol Rev. 2005;112:417445. 
8. Stroud CB, Davila J, Hammen C, Vrshek-SchallhornS. Severe and non-severe events in first onsets versus recurrences of depression: Evidence for stress sensitization. J Abnorm Psychol. 2011;120:142-154.

9. Larzelere RE, Cox RB, Smith GL. Do nonphysical punishments reduce antisocial behaviour more than spanking? a comparison using the strongest previous causal evidence against spanking. BMC Pediatrics. 2010;10:10.

10. Berlin LJ, Ispa JM, Fine MA, Malone PS, Brooks-Gunn J, Brady-Smith C, Ayoub C, Bai $Y$. Correlates and consequences of spanking and verbal punishment for lowincome white, African American and Mexican American toddlers. Child Devel. 2009;80:1403-1420.

11. Dodge KA, McLoyd VC, Lansford JE. The cultural context of physically disciplining children. In McLoyd VC, Hill NE, Dodge KA editors. African American family life: Ecological and cultural diversity). New York: Guilford. 2005;245-263.

12. Lansford JW, Deater-Deckard K, Dodge KA, Banes JE, Pettit GS. Ethnic differences in the link between physical discipline and later adolescent externalizing behaviours. J Child Psychol Psychiatry. 2004;45:801-812.

13. Slade EP, \& Wissow LS. Spanking in early childhood and later behavior problems: A prospective study of infants and young toddlers. Pediatrics. 2004;113:1321- 1330.

14. Baumrind D, Larzelere RE, Cowan PA. Ordinary physical punishment: Is it harmful? Comment on Gershoff (2002). Psychol Bull. 2002;128:580-589.

15. Gershoff ET, Grogan-Kaylor A, Lansford J E, Chang L, Zelli A, Deater-Deckard K, Dodge KA. Parent discipline practices in an international sample: associations with child behaviours and moderation by perceived normativeness. Child Developement. 2010;81:487-502.

16. Grogan-Kaylor A. Corporal punishment and the growth trajectory of children's antisocial behaviour. Child Maltreatment. 2005;10:283-292.

17. Seligman MEP. Helplessness: On depression, development and death. New York: W H Freeman; 1975.

18. Ryan RM, Deci EL. Self-determination theory and the facilitation of intrinsic motivation, social development, and well-being. Am Psychol. 2000;55:68-78.

19. Frodl T, Reinhold E, Koutsouleris N, Donohoe G, Bondy B, Reiser M, Möller H-J, Meisenzahl EM. Childhood stress, serotonin transporter gene and brain structures in major depression. Neuropsychopharmacology. 2010;35:1383-1390.

20. Pittenger C, Duman RS. Stress, depression, and neuroplasticity: A convergence of mechanisms. Neuropsychopharmacology. 2008;33:88-109.

21. Cappa C, Kahn SM. Understanding caregivers' attitudes towards physical punishment of children: Evidence from 34 low- and middle-income countries. Child Abuse Negl. 2011;35:1009-1021.

22. Long DE. Culture and customs of Saudi Arabia. Westport, Connecticut: Greenwood Press; 2005.

23. Trull TJ, Sher KJ, Minks-Brown C, Durbin J, Burr R. Borderline personality disorder and substance use disorders:: A review and integration. Clin Psychol Rev. 2000;20:235-253.

24. Brooner RK, King VL, Kidorf M, Schmidt CW, Bigelow GE. Psychiatric and substance use comorbidity among treatment-seeking opioid abusers. Arch Gen Psychiatry. 1997;54:71-80.

25. Kilpatrick DG, Ruggiero KJ, Acierno R, Sauders, BE, Resnick HS, Best CL. Violence and risk of PTSD, major depression, substance abuse/dependence and comorbidity: Results from the national survey of adolescents. J Consult Clin Psychol. 2003;71:692700. 
26. Higgins ET. Self-discrepancy: a theory relating self and affect. Psychol Rev. 1987;94:319.

27. First MB, Gibbon M. User's Guide for the Structured Clinical Interview for DSM-IV Axis II Personality Disorders: SCID-II. American Psychiatric Press: Arlington VA; 1997.

28. Kroenke K, Spitzer RL, Williams JBW, Löwe B. The Patient Health Questionnaire Somatic, Anxiety, and Depressive Symptom Scales: a systematic review. Gen Hosp Psychiatry. 2010;32:345-359.

29. Dwairy M, Achoui M, Abouserie R, Farah A, Sakhleh A, Fayad M, Khan H. Parenting styles in Arab societies. J Cross-Cultural Psychol. 2006;37:230-247.

30. Alloy LB, Abramson LY. Learned helplessness, depression and the illusion of control. J PersSoc Psychol. 1982;42:1114-1126.

31. Veijola J, Puukka, P, Lehtinen V, Moring J, Lindholm T, Vaeisaenen E. Sex differences in the association between childhood experiences and adult depression. Psychol Med. 1998;28:21-27.

32. Nelson DA, Hart $\mathrm{CH}$, Yang C, Olsen JA, Jin S. Aversive parenting in China: Associations with child physical and relational aggression. Child Development. 2006;77:554-572.

33. Miller, GE, Chen E, Parker KJ. Psychological stress in childhood and susceptibility to the chronic diseases of aging: Moving toward a model of behavioral and biological mechanisms. Psychol Bull. 2011;137: 959-997.

34. Afifi TO, Boman J, Fleisher W, Sareen J. The relationship between child abuse, parental divorce, and lifetime mental disorders and suicidality in a nationally representative adult sample. Child Abuse Negl. 2009;33:139-147.

35. Liu RT, Alloy LB. Stress generation in depression: A systematic review of the empirical literature and recommendations for future study. Clin Psychol Rev. 2010;30:582-593.

36. Irwin RR, Miller AH. Depressive disorders and immunity: 20 years of progress and discovery. Brain Behav Immun. 2007;21:374-383.

37. Pariante CM. Lightman SL. The HPA axis in major depression: classical theories and new developments. Trends in Neurosciences. 2008;31:464-468.

38. Hyland ME, Alkhalaf AM, Whalley B. Beating and insulting children as a risk for adult cancer, cardiac disease and asthma. J Behav Med. 2013;26:632-640.

(C) 2014 Hyland et al.; This is an Open Access article distributed under the terms of the Creative Commons Attribution License (http://creativecommons.org/licenses/by/3.0), which permits unrestricted use, distribution, and reproduction in any medium, provided the original work is properly cited.

\section{Peer-review history:}

The peer review history for this paper can be accessed here: http://www.sciencedomain.org/review-history.php?iid=371\&id=29\&aid=3314 